\title{
Comparative Analysis of Multidimensional Welfare Deprivation among Women in Rural and Urban South-South Nigeria
}

\author{
Oladokun Yetunde Olasimbo Mary'1, Kemisola Omorinre Adenegan1, Isaac Busayo Oluwatayo ${ }^{2}$ \\ ${ }^{1}$ Department of Agricultural Economics, Faculty of Agriculture, University of Ibadan, Ibadan, Nigeria \\ ${ }^{2}$ Department of Agricultural Economics and Animal Production, Faculty of Agriculture, University of Limpopo, \\ Limpopo, South Africa \\ Email: yetunde.oladokun@gmail.com
}

How to cite this paper: Mary, O.Y.O., Adenegan, K.O. and Oluwatayo, I.B. (2017) Comparative Analysis of Multidimensional Welfare Deprivation among Women in $\mathrm{Ru}-$ ral and Urban South-South Nigeria. Open Access Library Journal, 4: e4019. https://doi.org/10.4236/oalib.1104019

Received: October 11, 2017

Accepted: December 8, 2017

Published: December 11, 2017

Copyright $\odot 2017$ by authors and Open Access Library Inc.

This work is licensed under the Creative Commons Attribution International License (CC BY 4.0).

http://creativecommons.org/licenses/by/4.0/

\begin{abstract}
This study examined multidimensional welfare deprivation of women in rural and urban South-South (SS) Nigeria. Secondary data from Nigeria Demographic Health Survey (NDHS, 2013) was used for this study. A total number of 1965 women in rural and 1275 in urban South SS were covered in the study. Data analysis was done using descriptive statistics and fuzzy analysis. The mean age of women in rural SS was 34 years while in urban SS it was 28 years. The highest level of education attained by women in rural SS was complete primary education while in urban SS the women had complete secondary. This level of education had effect on their deprivation status because women in rural SS were less educated and more deprived than women in urban SS. In rural SS women have a mean household size of 6 while in the urban area women have a mean household size of 5 . The Deprivation index for rural women ranges from 0.05 to 0.89 with a mean value of 0.39 in rural SS and in urban SS the Deprivation index ranges from 0.19 to 0.96 with a mean of 0.29 . In the study area women had their Deprivation index between $0.000-0.9000$ in both rural and urban SS. Women in urban SS have high deprivation compared to the women in rural SS, this can also be related to their educational attainment because women in urban SS are more educated than women in rural SS. For women's deprivation status to be improved the rural community should be educated on the need to improve on their housing and sanitation characteristics and autonomy. Also interventions in the area of housing and sanitation characteristics and education should be made in urban SS.
\end{abstract}

\section{Subject Areas}

Economics 


\section{Keywords}

Deprivation, Multidimensional Poverty, South-South Nigeria, Welfare, Women

\section{Background/Problem Statement}

Deprivation can be referred to as a lack of socially defined necessities and the consequent social marginalization that is entailed, while the poor can be referred to as those who lack the resources to obtain the types of diet, participate in the activities and have the living conditions and amenities which are customary, or at least widely encouraged or approved, in the societies in which they belong [1]. It also emphasize the individual experience of discontent when being deprived of something to which one beliefs oneself to be entitled [2] [3] [4]. Welfare deprivation can be measured by an individual's possession of income, health, nutrition, education, assets, housing, and certain rights in a society such as freedom of speech. It also connotes lack of opportunities, powerlessness, and vulnerability. Women in Nigeria continue to be deprived and poor as a result of our socio cultural norms and belief that women are seen as second class citizen. Women have not been able to get and utilize opportunities such as ownership of assets, education that could better their lot and improve their welfare. As such there has been an increasing incidence of poverty and deprivation among rural women in the country because $70 \%$ of women are living below the poverty line.

Although giant strides have been made in reducing gender inequality in many African countries such as Nigeria, but women still face higher rates of poverty compared to their male counterparts [5]. Successive governments in the past at various levels have put in place measures and policies to drastically reduce the soaring rate of poverty and deprivation in the country especially among women through several programmes. Such policy measures according to [6] focus essentially on growth, basic needs, and rural development approaches, some of which were initiated before and after the independence. The period 1960 to 2009 witnessed several poverty alleviation policies, some of which include: Primary Health Care and Disease Programme (1982); Women Education Project (1986); Family Economic Advancement Programme (1997); Better Life For Rural Women programme (1987); Women in Health Development Project (1989); National Directorate of Employment (1986); National Poverty Eradication Programme (2001); National Economic Empowerment and Development Strategy NEEDS 2003; Seven Point Agenda (2009); and Nigeria Vision 20:2020 (2009). Also Non-Governmental Organisations (NGOs), States and Federal governments at various times rendered assistance to less privileged women and those in difficult situation by procuring and distributing skills acquisition/economic empowerment equipment to enable them improve their economic base, such assewing machine, embroidery machine, hair wash sink/basin, hair dryer, ther- 
mocool deep freezer, 5 horse power grinding machine, $2.7 \mathrm{KVA}$ thermocool generator, among others [7]. An inter-ministerial committee on women in agribusiness was constituted with the thrust of enhancing women's access to productive agricultural assets in the agricultural business. The committee ensured comprehensive appraisal of the skills acquisition centers nationwide in conjunction with the Federal Ministry of Lands, Housing and Urban Development. In addition, the committee/program is meant to ensure the attainment of the Millennium Development Goals (MDGs) 3, 4, 5 and 6 (Promoting gender equality and women empowerment; reduce child mortality and improve maternal health) through ambulance emergency intervention program; fight HIV/AIDS scourge and malaria disease as was put in place by the United Nations.

Some of the programs recorded certain level of successes; however, a number of them could not be sustained. Although some became moribund, others were replaced. Issues of corruption, political instability, policy inconsistencies, underfunding, duplication of roles of other agencies, policy reversals, and incompetence on the part of people appointed to serve as heads of programs were factors that militated against the successes of these initiatives. Also, all these programs never made great impact in effectively addressing the problem. In fact, welfare condition is becoming worse by the day and if drastic steps were not urgently taken towards effectively addressing poverty in Nigeria, especially among women, there is likely to be a wanton catastrophic impact on the country and perhaps the world. Without access to opportunities to further their education and interventions to improve their welfare, women will continue to disproportionately experience poverty in Nigeria [8] [9]. Thus, this calls for urgent concern.

Nigerians (65\%) live below the poverty line without any access to basic goods, services and commodities [10]. Since women constitute almost half of the population going by the latest population census in the country, it is convenient to say that most women are the victims of poverty in Nigeria today [11]. There have also been evidences that people in the rural area are more deprived or poorer than people in the urban areas. The rural poor account for $80 \%$ of African poverty, but urban poverty is substantial and appears to be growing [12].

People in the urban areas have access to amenities like electricity, roads, telecommunication among others than people in the rural areas. According to MPI $2014,85 \%$ of multidimensional poor live in rural areas [13].

Women are an important segment of the human population and constitute critical links between the present generation and the future. Appropriate investment in women's welfare has been shown to be of great benefit to the individual, household, and community. Such investment also benefits nations greatly in terms of poverty reduction, improved national economic performance, and realisation of the fundamental human rights of women [14]. Failure to accord the deserved attention to the welfare of women, on the other hand, carries grave implications for them, their children and households. 
Methodologically, several studies such as [15] [16] [17] [18] used Principal Component Analysis (PCA) to construct welfare indicators. However, for this study Fuzzy set analysis was used to estimate the deprivation status of women. The Fuzzy set analysis provides more flexibility in terms of involving conceptual and theoretical inputs and also leads to outputs that are easier to visualise and interpret [19]. The Fuzzy set also avoids jumps between two extremes but rather a gradation from one end of an attribute to another, a kind of discrete arrangement. This means that women would not just fall into the traditional dichotomy deprived and non-deprived but take into consideration degree of deprivation.

Appropriate investment in women's welfare has been shown to be of great benefit to the individual, household, and community. Such investment also benefits nations greatly in terms of poverty reduction, improved national economic performance, and realisation of the fundamental human rights of women [14]. Failure to accord the deserved attention to the welfare of women, on the other hand, carries grave implications for them, their children and households.

Understanding of welfare of women may have been a driving force for welfare deprivation among women which has warranted this study. More so, the SDG underscores the multidimensional nature of welfare deprivation as it dominates the goals set by the United Nations. The first SDG reflected the income dimension of welfare, to end poverty in all its forms everywhere from 2015-2030 while the other SDGs focused on non-income dimensions of well-being: education, health, access to water and sanitation. Reducing women's deprivation needs the contributions of both the public and private sectors of the economy and international partners, and also adequate social protection policies should be put in place in the country. Therefore, the study provided empirical evidence on the deprivation status of women in rural and urban SS. This is geared towards proffering necessary intervention strategies to reducing the inherent deprivations experienced by rural women.

It is against this background that this study is comparing welfare deprivation by women in rural and urban South-South (SS) region in Nigeria. It is in view of this that this study proffered answers to these research question; What is the welfare deprivation status of women in rural and urban South-South.The main objective of this study is to examine the welfare deprivation of women in rural and urban South-South Nigeria.

\section{Theoretical Framework and Literature Review}

\subsection{Theoretical Framework}

\section{Relative Deprivation Theory}

Feelings of deprivation are relative, as they come from a comparison to social norms that are not absolute and usually differ from time and place. This differentiates relative deprivation from objective deprivation (also known as absolute deprivation or absolute poverty) - a condition that applies to all underprivileged people. This leads to an important conclusion: while the objective deprivation 
(poverty) in the world may change over time, relative deprivation will not, as long as social inequality persists and some humans are better off than others.

Relative deprivation theory refers to the idea that feelings of deprivation and discontent are related to a desired point of reference (i.e. reference groups). Feelings of relative deprivation arise when desires become legitimate expectations and those desires are blocked by society. Social satisfaction is the opposite of relative deprivation. Relative deprivation is generally considered to be the central variable in the explanation of social movements and is used to explain the quest for social change that inspires social movements; social movements emerge from collective feelings of relative deprivation [20]. Relative deprivation theory focuses on feelings and actions. For example, the theory encourages the exploration of an individual's feelings of deprivation that may result from comparing his or her situation with that of a referent person or group as well as the behavioural effects of deprivation feelings. In particular, relative deprivation theory is the foundation of multiple theories of social psychology including frustration, aggression theory, equity theory, social comparison theory, and reference group theory.

Deprivation theory means that people who are deprived of things deemed valuable in society whether money, justice, status or privilege to join social movements with the hope of redressing their grievances. This is a beginning point for looking at why people join social movements; however, it is even more important to look at relative deprivation theory, a belief that people join social movement based on their evaluations of what they think they should have compared with what others have. On the contrary, absolute deprivation is people's actual negative condition; relative deprivation is what people think they should have relative to what others have, or even compared with their own past or perceived future. Improved conditions fuel human desires for even better conditions, and thus can spark revolutions. The central idea of relative deprivation theory suggests that individuals or groups feel deprived when their current circumstances are negatively compared to the situation of others. In this study women deprivation are measured based on some dimensions as compared to what is acceptable in the society which is what this theory is about.

\subsection{Literature Review}

[21] in his work on multidimensional measurement of poverty among women in Sub-Saharan Africa opined that since the seminal work of Sen, poverty has been recognized as a multidimensional phenomenon. The recent availability of relevant databases renewed the interest in this approach. This paper estimates multidimensional poverty among women in fourteen Sub-Saharan African countries using the Alkire and Foster multidimensional poverty measures, whose identification method is based on a counting approach. Four dimensions are considered: assets, health, schooling and empowerment. The results show important differences in poverty among the countries of the sample. The multidimensional poverty estimates are compared with some alternative measures such as the 
Human Development Index, income poverty, asset poverty and the Gender-related Development Index. It is found that including additional dimensions into the analysis leads to country rankings different from those obtained with the mentioned four measures. Decompositions by geographical area and dimension indicate that rural areas are significantly poorer than urban ones and that a lack of schooling is, in general, the highest contributor to poverty. The paper also conducts robustness and sensitivity analyses of the multidimensional estimates with respect to the number of dimensions in which deprivation is required in order to be considered poor, as well as to the poverty lines within each dimension. Several cases of dominance between countries are found in the first robustness test.

[7] used the fuzzy set approach to analyse multidimensional well-being of women in rural Nigeria using the 2008 Demographic and Health Survey data. The study decomposed multidimensional well-being across the zones, states, and the socio-economic groups of rural households. It further decomposed the absolute and relative contributions of welfare indicator to multidimensional wellbeing. The result shows that the multidimensional well-being for women in rural Nigeria is 0.34 . In summary, middle-aged women with higher education from a small sized female-headed household employed in the non-agricultural sector have higher wellbeing indices than other groups. It was concluded that intervention should be made in the area of education and access to information, employment, autonomy and these interventions should take cognizance of the culture of women especially in the northern part.

[22] estimated the multidimensional poverty indices for women and children in Kenya using two dimensions of wellbeing. The Alkire and Foster's (2007) counting approach was used to measure multidimensional poverty in two dimensions of health and assets, and a bi-probit model was used to explain multidimensional poverty. The result of the analysis shows that the highest contribution to multidimensional poverty is from assets relative to health, rural sector relative to urban sector and boys relative to girls.

[23] present empirical evidence on the deprivation costs of the 2001 to 2002 Argentinean crisis. The selected approach was multidimensional and focused on four aspects of quality of life: labour, assets, education and income. These dimensions were constructed by multivariate data reduction techniques and then aggregated using the Bourguignon and Chakravarty's (2003) axiomatic multidimensional poverty measure. The main findings indicate that the crisis had larger costs on wellbeing dimensions tied to the economic cycle, such as income and labour. Costs were mild on structural aspects of wellbeing, such as assets and education.

\section{Methodology}

\subsection{Study Area}

The area of study for this research is rural and urban SS Nigeria. South-South 
geopolitical zone is one of the six geopolitical zones in Nigeria. Secondary data from [24] was used for this study. The sample for the 2013 NDHS was a stratified sample, selected independently in three stages from the sampling frame. Stratification was achieved by separating each state into urban and rural areas. A total number of 1965 women in rural and 1275 in urban SS were covered in this survey.

\subsection{Analytical Procedure}

Descriptive statistics fuzzy set theory and logit regression were used in this study. The descriptive statistics used include percentages, frequency distribution tables, and the mean.

\subsection{Fuzzy Set Analysis}

This was used to estimate the deprivation status of women. The fuzzy set substitutes the characteristic function of a crisp set that assigns a value of 1 or 0 . Large values denote high degree of membership [25] [26]. The degree of deprivation is shown by the placement of the individual on the 0 or 1 value or other values in-between. The model is considered as follows:

Assume a population $A$ of $n$ individuals, $A=\left(a_{1}, a_{2}, a_{3}, \cdots, a_{n}\right)$. A fuzzy subset $B$ includes all individuals with $a_{i} \in B$. The degree of deprivation of the ith individual $(i=1, \cdots, n)$ with respect to a particular attribute $j$ given that $(j=1, \cdots, m)$ is defined as:

$$
\mu_{\beta}\left|x_{j}\left(a_{i}\right)\right|=x_{i j}, 0 \leq x_{i j} \leq 1
$$

where:

$x_{i j}=1$; condition of total lack of welfare attribute (state of deprivation).

$x_{i j}=0$; condition of full possession of welfare attribute.

$0 \leq x_{i j} \leq 1$; conditions within the range of lack and full possession.

The variables that define indicators of welfare are either dichotomous or categorical in nature.

\subsubsection{Dichotomous Variables}

Dichotomous variables are answered by either "Yes" or "No"; with the "yes" being a state of well being and the No, a state of deprivation. Following [27], from a universal set of A individuals, we define the membership function of fuzzy subset of B for the $I^{\text {th }}$ individual

$$
(i=1, \cdots, n) \text { that possesses the } f^{\text {th }} \text { welfare attribute }(j=1, \cdots, m) \text { as: }
$$

$$
\mu_{\beta}\left|x_{j}\left(a_{i}\right)\right|=x_{i j},
$$

$x_{j}\left(a_{i}\right)$ is the $m$ order of welfare attributes that will result in a state of welfare if totally or partially owned by the $a_{i}^{\text {th }}$ household.

$x_{i j}=1$, if the $a_{i}^{\text {th }}$ woman possess the $f^{\text {th }}$ attribute (that is she completely has the welfare attribute).

$x_{i j}=0$ if the $a_{i}^{\text {th }}$ woman does not possess the welfare attribute. 


\subsubsection{Categorical Variables}

Categorical variables present themselves in a range of values, rather than just two values. Expressing the membership function for these variables take the form:

$$
\mu_{\beta}\left|x_{j}\left(a_{i}\right)\right|=x_{i j}
$$

In a general case of $C=C_{\min }$ to $C_{\max }$ ordered categories of some welfare indicator with $C_{\min }$ being the highest level of deprivation and $C_{\max }$ represents the lowest level of deprivation. If the modalities are arranged in decreasing order of deprivation attainment from $C_{\min }$ to $C_{\max }, C_{i}$ values represent the intermediate values within the two thresholds, which depicts the position of the $I^{\text {th }}$ individual within the modalities.

$$
x_{i j}=C_{\min }-C_{i} / C_{\min }-C_{\max } \text {, if } C_{\max } \leq C_{i j} \leq C_{\min }
$$

so that $0 \leq x_{i j} \leq 1$

In specifying the well-being index for the population of women, following [7] [28] it is expressed as:

$$
\mu_{\beta}\left(a_{i}\right)=\sum_{j=1}^{n} x_{i j} w_{j} \mid \sum_{j=1}^{m} w_{j}
$$

where $w_{j}$ is the weight given to the $f^{\text {th }}$ attribute. $\mu_{\beta}\left(a_{i}\right)$ measures the degree of well-being of the $i^{\text {th }}$ individual as a weighting function of $\mathrm{m}$ attributes/indicators.

Table 1 shows Selected Dimensions and Methods of Evaluation that were used for this study.

\section{Results and Discussion}

In Table 2, the highest percentage (46.90) of women in rural SS are within the age range of $35-49$ while in the urban area $40.93 \%$ of women fall within the age range of $15-24$ The mean age of women in rural SS is 34 years while in urban SS is 28 years. This implies that we have older women in rural area as compared to the urban area. Younger women tend to be in the urban areas because they attend colleges and universities here and they tend to get white collar jobs too. The highest percentage of women in rural SS have complete primary education (28.80\%) while in the urban SS a higher percentage has complete secondary (33.61\%), implying that urban women are more educated. In rural SS women have a mean household size of 6 while in the urban area women have a mean household size of 5 . Women in urban areas know the implication of having a large household size and since they are educated, have collar jobs they do not have time to take care of many children while women in rural area can afford to have medium to large household size since they can use this as family labour and they can afford to carry their children to the farm and take care of them. Most of the women in rural and urban SS are employed $(83.96 \%, 63.585 \%)$. There are more employed women in rural SS than in urban because most of the women in urban SS are young and are probably in school or learning a trade.

In Table 3, $14.03 \%$ and $13.05 \%$ of rural and urban women in SS receive antenatal care from skilled attendants. Also, only $22.32 \%$ and $25.07 \%$ of women 
Table 1. Selected dimensions and method of evaluation.

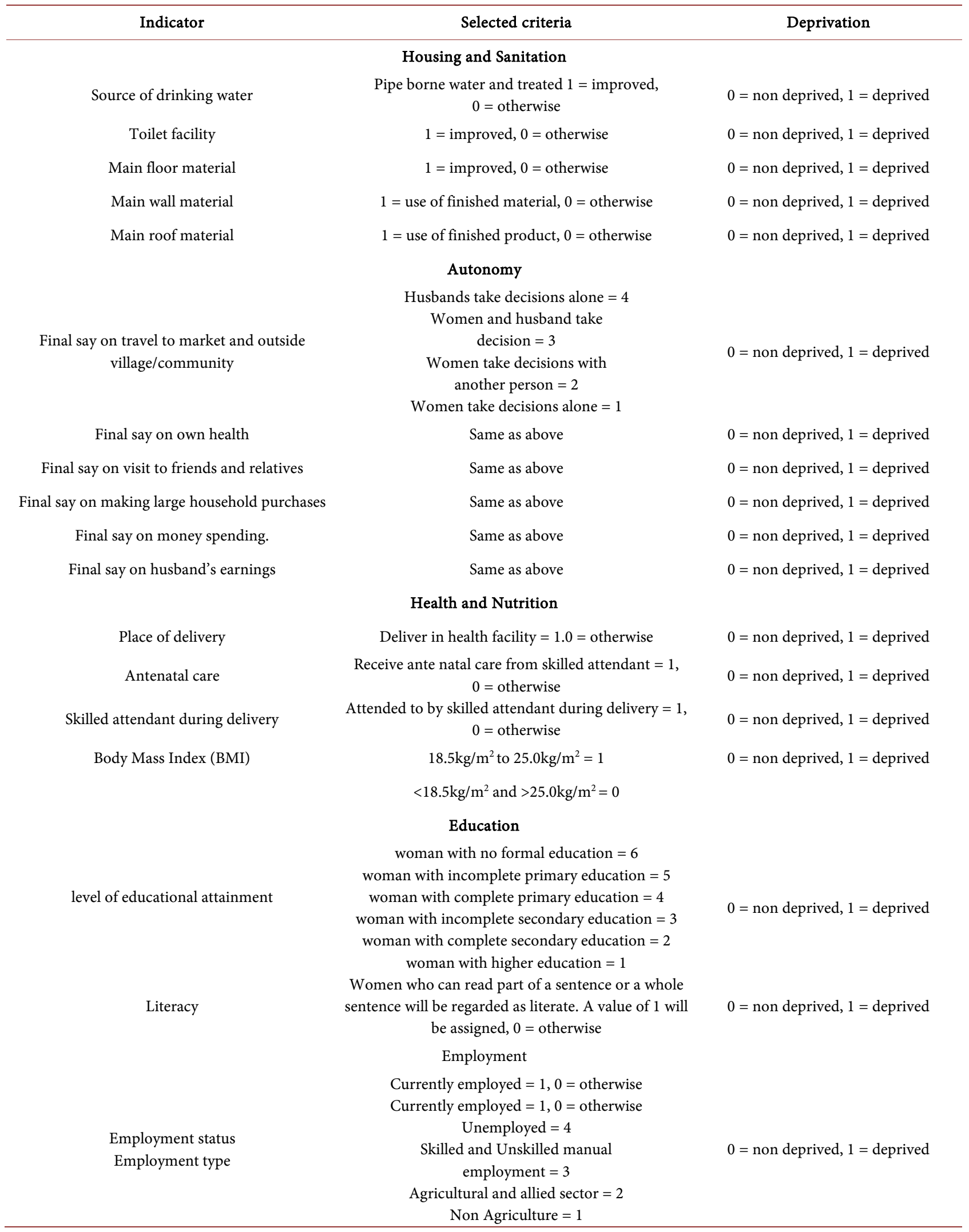

Source: Author's computation from the 2013 NDHS data. 
Table 2. Distribution of women according to their Socio economic characteristics in rural and urban South-South Nigeria.

\begin{tabular}{|c|c|c|c|c|}
\hline \multicolumn{3}{|c|}{ Rural } & \multicolumn{2}{|c|}{ Urban } \\
\hline Variable & Frequency & $\%$ & Frequency & $\%$ \\
\hline \multicolumn{5}{|l|}{ Age } \\
\hline $15-24$ & 397 & 15.69 & 314 & 15.23 \\
\hline $25-34$ & 947 & 37.42 & 821 & 39.82 \\
\hline $35-49$ & 1187 & 46.90 & 927 & 44.96 \\
\hline Mean & 34 & & 28 & \\
\hline Standard deviation & 8 & & 10 & \\
\hline \multicolumn{5}{|l|}{ Educational attainment } \\
\hline No education & 261 & 10.31 & 56 & 2.72 \\
\hline Incomplete primary & 261 & 10.31 & 111 & 5.38 \\
\hline Complete primary & 729 & 28.80 & 248 & 12.03 \\
\hline Incomplete secondary & 558 & 22.05 & 566 & 27.45 \\
\hline Complete secondary & 544 & 21.49 & 693 & 33.61 \\
\hline Higher & 178 & 7.03 & 388 & 18.82 \\
\hline \multicolumn{5}{|l|}{ Household size } \\
\hline $1-5$ & 1387 & 54.80 & 1225 & 59.41 \\
\hline $6-10$ & 1027 & 40.58 & 737 & 35.74 \\
\hline$>10$ & 117 & 4.62 & 100 & 4.85 \\
\hline Mean & 6 & & 5 & \\
\hline Standard Deviation & 3 & & 3 & \\
\hline \multicolumn{5}{|l|}{ Marital status } \\
\hline Single & 300 & 11.85 & 250 & 12.12 \\
\hline Married & 2231 & 88.15 & 1812 & 87.88 \\
\hline \multicolumn{5}{|l|}{ Occupation type } \\
\hline Unemployed & 406 & 16.04 & 751 & 36.42 \\
\hline Skilled and Unskilled & 120 & 4.74 & 123 & 5.97 \\
\hline Agriculture and allied & 764 & 30.19 & 159 & 7.71 \\
\hline Services & 1241 & 49.03 & 1029 & 49.90 \\
\hline Total & 2531 & 100 & 2062 & 100 \\
\hline
\end{tabular}

Source: Authors' computation from the 2013 NDHS data.

deliver in health facilities in rural and urban SS. Only $2.21 \%$ and $22.60 \%$ of women were assisted by skilled health personnel during delivery. In spite of government efforts to achieve the SDGs, rural women largely patronise traditional birth attendants and some even prefer to deliver at home without assistance. Little wonder why maternal mortality is on the increase in the rural areas. Also, the table shows that (43.07\% and $46.61 \%)$ of women have normal body mass index. 
Table 3. Distribution of rural women by their health and nutrition status.

\begin{tabular}{ccccc}
\hline & \multicolumn{2}{c}{ Rural } & \multicolumn{2}{c}{ Urban } \\
\hline Category & Frequency & Per cent & Frequency & Percent \\
\hline Antenatal care & & & & \\
Skilled Attendant & 355 & 14.03 & 269 & 13.05 \\
Non Skilled Attendant & 2176 & 85.97 & 1793 & 86.95 \\
Assistance during delivery & & & & \\
Skilled Attendant & 56 & 2.21 & 466 & 22.60 \\
Non Skilled Attendant & 2475 & 97.79 & 1596 & 77.40 \\
Place of delivery & & & & \\
Health facility & 565 & 22.32 & 517 & 25.07 \\
Non health facility & 1966 & 77.68 & 1545 & 74.93 \\
Body Mass Index & & & & \\
Normal & 1090 & 43.07 & 961 & 46.61 \\
Abnormal (Thin and Obese) & 1441 & 56.93 & 1101 & 53.39 \\
\hline
\end{tabular}

Source: Authors' computation from the 2013 NDHS data.

Table 4 shows that in rural SS $34.69 \%$ women have autonomy on how they spend their money compared to $21.44 \%$ in urban SS. With regards to health $9.25 \%$ of women in rural SS have autonomy while $6.06 \%$ have autonomy in urban SS.

\section{Multidimensional Welfare Deprivation of Women}

Table 5 shows the distribution of rural women based on their Deprivation status. The Deprivation Index (DI) for rural women ranges from 0.05 to 0.89 with a mean value of 0.39 in rural SS and in urban SS the DI ranges from 0.19 to 0.96 with a mean of 0.29 . Most of the women had their DI between $0.00-0.90$ in both rural and urban SS.

The contribution of each welfare dimension to women's deprivation is presented in Figure 1 and Figure 2. Among the six dimensions considered in rural SS, housing and sanitation had the highest absolute and relative contributions of $0.13 \%$ and $32.03 \%$ and thus contributes the least to deprivation. This is followed by autonomy with $0.08 \%$ and $20.99 \%$. This means that rural women are better off in these dimensions than others. The high relative contribution of housing is expected since most of them live in the same house with their spouses. The houses were provided by the joint effort of the household. It is also worthy of note that autonomy has a high relative contribution. The high relative contribution of autonomy underscores the point that power relations within the household is crucial and ability to participate in decision making particularly with respect to self is important for women's welfare. In urban SS, housing and sanitation had the highest absolute and relative contributions of $0.09 \%$ and $32.74 \%$ 


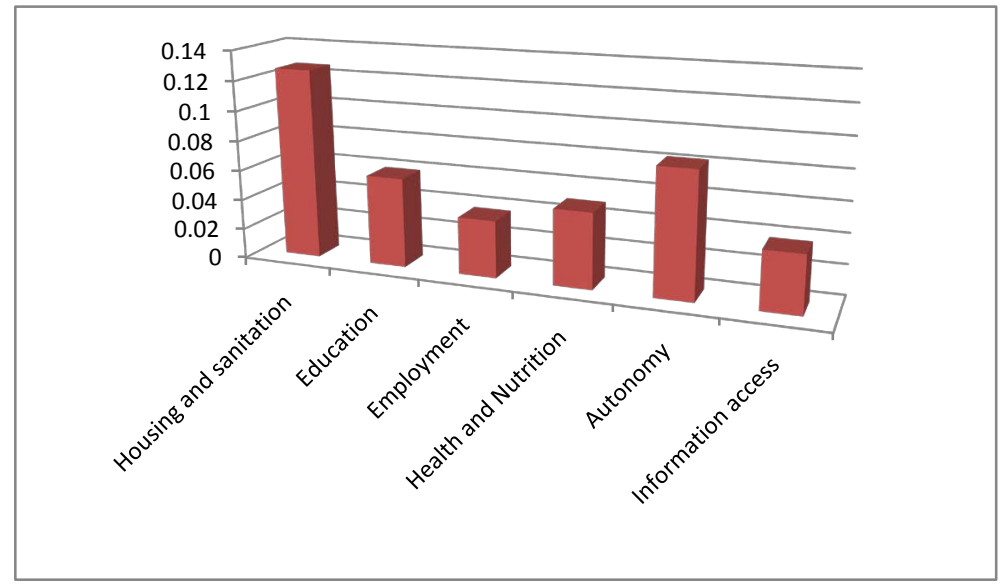

Figure 1. Contribution of Dimensions to deprivation in rural South-South. Source: Authors' computations from the 2013 DHS data.

Table 4. Distribution of rural women by autonomy.

\begin{tabular}{|c|c|c|c|c|}
\hline \multirow[b]{2}{*}{ Category } & \multicolumn{2}{|c|}{ Rural } & \multicolumn{2}{|c|}{ Urban } \\
\hline & Frequency & $\%$ & Frequency & $\%$ \\
\hline \multicolumn{5}{|c|}{ Decision maker on spending money } \\
\hline Respondents alone & 878 & 34.69 & 442 & 21.44 \\
\hline Respondents and Partner & 522 & 20.62 & 283 & 13.72 \\
\hline Husband/partner alone & 1125 & 44.45 & 1337 & 64.84 \\
\hline Someone else and others & 6 & 0.24 & 0 & 0.00 \\
\hline \multicolumn{5}{|l|}{ Decision maker on own health } \\
\hline Respondents alone & 234 & 9.25 & 125 & 6.06 \\
\hline Respondents and Partner & 994 & 39.27 & 608 & 29.49 \\
\hline Husband/partner alone & 1285 & 50.77 & 1326 & 64.31 \\
\hline Someone else and others & 18 & 0.71 & 3 & 0.15 \\
\hline \multicolumn{5}{|c|}{ Decision on large household purchases } \\
\hline Respondents alone & 374 & 14.78 & 125 & 6.06 \\
\hline Respondents and Partner & 1101 & 43.50 & 608 & 29.49 \\
\hline Husband/partner alone & 1041 & 41.13 & 1326 & 64.31 \\
\hline Someone else and others & 15 & 0.59 & 3 & 0.15 \\
\hline \multicolumn{5}{|c|}{ Decision on visit to family/relatives } \\
\hline Respondents alone & 268 & 10.59 & 112 & 5.43 \\
\hline Respondents and Partner & 1204 & 47.57 & 679 & 32.93 \\
\hline Husband/partner alone & 1045 & 41.29 & 1263 & 61.25 \\
\hline Someone else and others & 14 & 41.29 & 8 & 0.39 \\
\hline
\end{tabular}

Source: Authors' computation from the 2013 NDHS data.

and thus contributes the least to deprivation. This is followed by education with $0.04 \%$ and $14.96 \%$. This means that urban women are better off in these dimensions than others. 


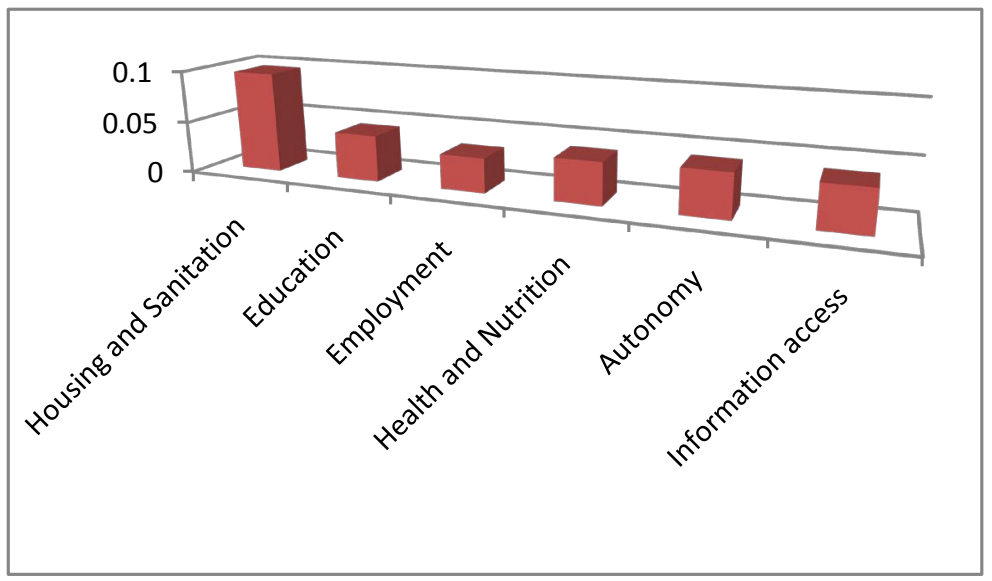

Figure 2. Contribution of Dimensions to deprivation in urban SS. Source: Authors' computation from the 2013 NDHS data.

Table 5. Distribution of rural women by their deprivation index.

\begin{tabular}{ccccc}
\hline & \multicolumn{2}{c}{ Rural } & \multicolumn{2}{c}{ Urban } \\
\hline Deprivation Index & Frequency & $\%$ & Frequency & $\%$ \\
\hline $0.0000-0.1000$ & 24 & 0.95 & 157 & 7.61 \\
$0.1001-0.2000$ & 212 & 8.38 & 537 & 26.04 \\
$0.2001-0.3000$ & 534 & 21.10 & 601 & 29.15 \\
$0.3001-0.4000$ & 600 & 23.71 & 324 & 15.71 \\
$0.4001-0.5000$ & 536 & 21.18 & 168 & 8.15 \\
$0.5001-0.6000$ & 346 & 13.67 & 97 & 4.70 \\
$0.6001-0.7000$ & 185 & 7.31 & 90 & 4.36 \\
$0.7001-0.8000$ & 82 & 3.24 & 67 & 3.25 \\
$0.8001-0.9000$ & 12 & 0.47 & 16 & 0.78 \\
$0.9001-1.0000$ & 0 & 0.00 & 5 & 0.24 \\
Total & 2531 & 100 & 2062 & 100 \\
\hline
\end{tabular}

Source: Authors' computation from the 2013 NDHS data.

The decompositions across states as shown in Figure 3 and Figure 4 in rural SS reveal that Cross river and Delta are the most deprived states while in urban SS Bayelsa and Delta are the most deprived.

In ascending order of contribution, the six dimensions considered are arranged as follows in rural SS: employment, information access, health and nutrition, education, autonomy, housing and sanitation. While in the urban in ascending order the dimensions are arranged thus employment, health and nutrition, information access, autonomy, education, housing and sanitation. In view of the high deprivation index of women in general, these dimensions need to be improved on particularly information access, education, health and nutrition whose contributions to deprivation are high. The Levene's test shows that the variances of multidimensional well-being indices across dimensions are significantly different $(p=0.0000)$. 


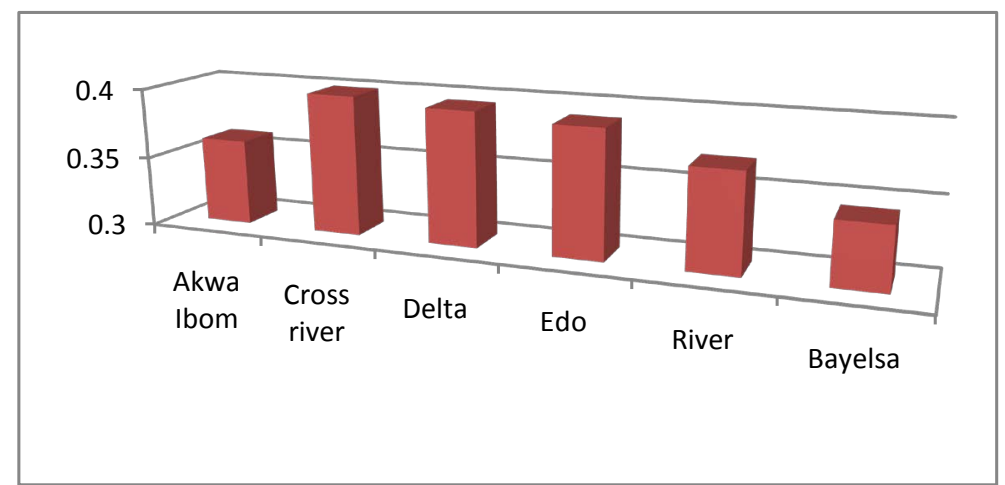

Figure 3. Multidimensional Wellbeing Decomposition across States in rural SS. Source: Authors' computation from the 2013 NDHS data.

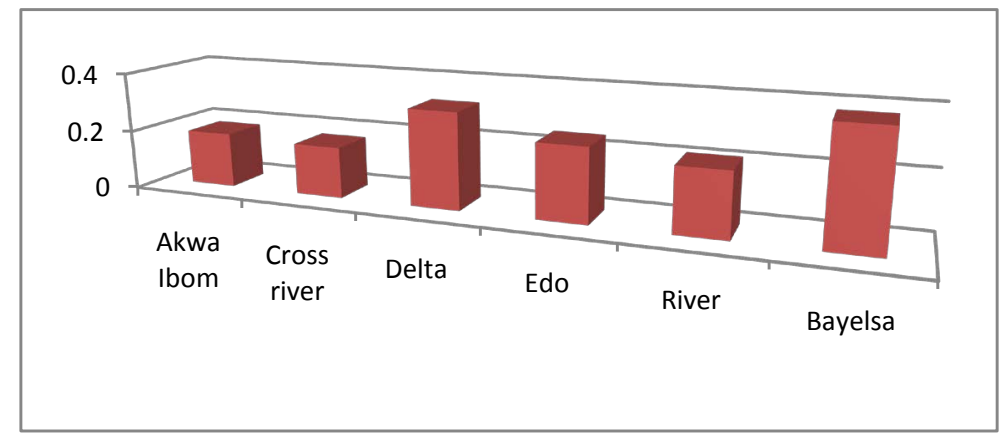

Figure 4. Multidimensional Wellbeing Decomposition across States in urban SS. Source: Authors' computation from the 2013 NDHS data.

\section{Conclusion}

The Deprivation Index (DI) for rural women ranges from 0.05 to 0.89 with a mean value of 0.39 in rural SS while in urban SS the DI ranges from 0.19 to 0.96 with a mean of 0.29 . Thus, women in rural SS $(D I=0.39)$ are more deprived than women in urban SS (DI $=0.29$ ).

\section{Recommendation}

Interventions are needed in the areas of autonomy, education, housing and sanitation characteristics. Improvement in girl child education will enhance their earning power and reduce their level of education in urban SS. Concerted efforts are required from non-governmental organisations and local institutions to give women more voice and opportunities to participate in decision making by encouraging them to join peer groups.

\section{References}

[1] Townsend, P. (1979) Poverty in the United Kingdom. A Survey of Household Resources and Standards of Living. Harmondsworth, Penguin Books.

[2] Bayertz, K. (1999) Solidarity, Springer, Google Print, 144. https://doi.org/10.1007/978-94-015-9245-1

[3] Walker, I. and Smith, H.J. (2001) Relative Deprivation: Specification, Development, 
and Integration. Cambridge University Press. https://doi.org/10.1017/CBO9780511527753

[4] Schaefer, R.T. (2008) Racial and Ethnic Groups. 11th Edition, Pearson Education, 69.

[5] Curley, J., Ssewamala, F.M., Nabunya, P., Llic, V. and Keun, H.C. (2016) Child Development Accounts (CDAs): An Asset-Buiding Strategy to Empower Girls in Uganda. International Social Work, 59, 18-31. https://doi.org/10.1177/0020872813508569

[6] Ogwumike, F.O. (2001) Profile and Dimension of Poverty in Nigeria. In NCEMA Workshop on Poverty Alleviation Policies and Strategies, 15th-26th, October.

[7] Adeoti, A.O. and Akinwande, B. (2013) Poverty and Wellbeing of Women in Rural Nigeria. LAP LAMBERT Academic Publishing, VDM Verlags Service Gesellschaf.

[8] African Union (2004) The Road to Gender Inequality in Africa: An Overview. Report, Addis Ababa Ethiopia.

[9] Ssewamala, F.M. (2004) Expanding Women's Opportunities: The Potential of Heifer Projects in Sub-Saharan Africa. Development in Practice, 14, 550-559. https://doi.org/10.1080/09614520410001686133

[10] National Bureau of Statistics (NBS) (2012) The Nigeria Poverty Profile 2010 Report. http://www.nigerianstat.gov.ng/pdfuploads/Nigeria\%20Poverty\%20Profile\%202010. pdf

[11] Usman, U.S. (2015) Women and Poverty in Nigeria: Agenda for Poverty Eradication. Developing Country Studies, 5, 122-126.

[12] World Bank (2001) World Development Report. Oxford University Press, Oxford.

[13] Alkire, S., Chatterjee, M., Conconi, A., Seth, S. and Vaz, A. (2014) Poverty in Rural and Urban Areas Direct Comparisons Using the Global MPI 2014. OPHI Report.

[14] UN (2010) The Millenium Development Goals Report 2010 United Nations.

[15] Ologbon, O.A.C., Idowu, A.O., Oyebanjo, O. and Akerele, E.O. (2014) Multidimensional Poverty Characteristics among Riverine Households in Southwestern Nigeria. Journal of Sustainable Development in Africa, 16, 126-144.

[16] Ologbon, O.A.C., Adeoti, A.I., Omonona, B.T. and Falusi, A.O. (2012) Welfare Deprivation among Riverine Households in Southwestern Nigeria. Journal of Agricultural and Biological Science, 7, 330-341.

[17] Asselin, L.-M. (2002) Multidimensional Poverty: Composite Indicator of Multidimensional Poverty. Institut de Mathématique Gauss, Lévis.

[18] Sahn, D.E. and Stifel, D.C. (2000) Poverty Comparisons over Time and across Countries in Africa. World Development, 28, 2123-2155. https://doi.org/10.1016/S0305-750X(00)00075-9

[19] Sonia, F.H. (2014) Asset-Based Poverty Analysis in Rural Bangladesh: A Comparison of Principal Component Analysis and Fuzzy Set Theory.

[20] Morrison, D. (1971). Some Notes toward Theory on Relative Deprivation, Social Movements, and Social Change. The American Behavioral Scientist, 14, 675.

[21] Batana, Y.M. (2013) Multidimensional Measurement of Poverty among Women in Sub-Saharan Africa. Social Indicators Research, 112, 337-362. https://doi.org/10.1007/s11205-013-0251-9

[22] Kabubo-Mariara, J., Linderhof, V., Kruseman, G., Atieno, R. and Mwabu, G. (2010) Poverty-Environmental Links: The Impact of Soil and Water Conservation and Tenure Security on Household Welfare in Kenya. Journal of Development and 
Agricultural Economics, 2, 41-53.

[23] Conconi, A. and Ham, A. (2010) The Many Faces of Poverty: Quantifying the Deprivation Cost of the 2001-2002 Crisis in Argentina. Económica, 56, 29-67.

[24] DHS (2013) Nigeria Demographic and Health Survey.

[25] Martinetti, E.C. (2000) A Multidimensional Assessment of Wellbeing Based on Sen's Functioning Approach. Rivista Internazionale di Scienze Sociali, 108, 207-239.

[26] Majumder, A. (2006) The State and Plight of Indian Women: A Multidimensional Assessment of Well-Being Based on Sen's Functioning Approach. In: International Conference of the Human Development and Capability Association: Freedom and Justice, Groningen, September 2006.

[27] Oni, O.A. and Adepoju, T.A. (2011) A Capability Approach to the Analysis of Rural Households' Wellbeing in Nigeria. MPRA Paper No. 34508.

[28] Oyekale, A.S. and Okunmadewa, F.Y. (2008) Fuzzy Set Approach to Multidimensional Poverty Analysis in Abia State, Nigeria. Journal of Applied Sciences, 3, 490-495. 